\title{
HUBUNGAN ANTARA PENGGUNAAN COTTON BUD DENGAN GANGGUAN PENDENGARAN TERHADAP PASIEN SERUMEN OBSTURAN DI RS PERTAMINA BINTANG AMIN BANDAR LAMPUNG
}

\author{
Fasty Ladyani Mustofa ${ }^{1}$, Jordy Oktobiannobel ${ }^{2^{*}}$, Fatah Satya Wibawa ${ }^{3}$, Sri \\ Megawati $^{4}$
}

\author{
1,2,3Teaching staff, Faculty of Medicine, Malahayati University, Lampung \\ ${ }^{4}$ Medical Student, Faculty of Medicine, Malahayati University, Lampung \\ Email Koresponden: srimaria13pl@yahoo.com
}

\section{ABSTRACT: THE RELATIONSHIP BETWEEN THE USE OF COTTON BUD AND HEARING DISORDER TO OBSTURAN SERUMEN PATIENTS AT PERTAMINA BINTANG AMIN BANDAR LAMPUNG HOSPITAL}

Introduction: data presented by Riskesdas (2013) shows that the prevalence of cerumen obstacle in Indonesia is $18.8 \%$. The prevalence at Pertamina Bintang Amin Hospital in Bandar Lampung is 17,205 patients with obstetric cerumen. Cotton buds are commonly used to clean ears from Serumen and cases of itching in the ears in the community. Cotton buds are not only used by adults, but also used by children.

Purpose: research objectives to determine the relationship between the use of cotton buds with obsturan cerumen at Pertamina Bintang Amin Hospital, Bandar Lampung.

Method: this type of research is quantitative, analytic observational design with a cross sectional approach. The population was 390 patients with obstetric cerumen taken from a questionnaire at Pertamina Bintang Amin Hospital, Bandar Lampung. Retrieval of data using a questionnaire. The data analysis technique used the Chi-square statistical test.

Result: showed that out of 390 obsturan cerumen patients, most of the use of cotton buds was not good, namely 200 people (51.3\%), most of the use of obsturan cerumen closed the hole, as many as 222 people (56.9\%). There is a relationship between the use of cotton buds and obsturan cerumen at Pertamina Bintang Amin Hospital in Bandar Lampung.

Conclusion: there is a relationship between the use of cotton buds and obsturan cerumen at Pertamina Bintang Amin Hospital in Bandar Lampung ( $p$ value 0.000, OR 2.459). It is advisable to carry out ear care appropriately so that obstructive cerumen does not arise which can cause hearing loss.

Keywords: Cotton Bud, Obstetric Serumen

INTISARI: HUBUNGAN ANTARA PENGGUNAAN COTTON BUD DENGAN GANGGUAN PENDENGARAN TERHADAP PASIEN SERUMEN OBSTURAN DI RS PERTAMINA BINTANG AMIN BANDAR LAMPUNG

Latar belakang: ata yang disajikan Riskesdas (2013) bahwa prevalensi kejadian serumen obsturan di Indonesia sebesar 18,8\%. Prevalensi di RS Pertamina Bintang Amin Bandar Lampung mendapatkan pasien serumen obsturan sebanyak 17.205 orang. Cotton bud biasa digunakan untuk membersihkan telinga dari Serumen 
dan kasus gatal pada telinga di kalangan masyarakat. Cotton bud tidak hanya digunakan oleh orang dewasa, tetapi juga digunakan oleh anak-anak.

Tujuan: diketahui hubungan penggunaan cotton bud dengan serumen obsturan di RS Pertamina Bintang Amin Bandar Lampung.

Metode penelitian: Jenis penelitian kuantitatif, rancangan analitik observasional dengan pendekatan cross sectional. Populasi yaitu 390 orang pasien serumen obsturan yang diambil dari kuisioner di RS Pertamina Bintang Amin Bandar Lampung. Pengambilan data menggunakan kuesioner. Teknik analisis data menggunakan uji statistik Chi-square.

Hasil: menunjukkan bahwa dari 390 pasien serumen obsturan sebagian besar penggunaan cotton budnya tidak baik yaitu sebanyak 200 orang $(51,3 \%)$, sebagian besar penggunaan serumen obsturan menutup lubang yaitu sebanyak 222 orang (56,9\%). Ada hubungan penggunaan cotton bud dengan serumen obsturan di RS Pertamina Bintang Amin Bandar Lampung.

Kesimpulan: ada hubungan penggunaan cotton bud dengan serumen obsturan di RS Pertamina Bintang Amin Bandar Lampung ( $p$ value 0,000, OR 2,459). Disarankan melakukan perawatan telingan dengan tepat sehingga tidak timbul serumen obsturan yang dapat menyebabkan gangguan pendengaran.

Kata Kunci : Cotton Bud, Serumen Obsturan

\section{PENDAHULUAN}

Serumen obsturan atau kotoran telinga adalah produk kelenjar sebasea dan apokrin yang ada pada kulit liang telinga dalam kondisi menumpuk dan keras. Pengerasan serumen atau kotoran telinga ini lebih sering terjadi pada anak-anak dan orang dewasa atau remaja. Sebenarnya fungsi utama serumen ini adalah untuk menghalangi serangga yang masuk ke dalam tubuh kita, namun serumen tidak bersifat anti jamur dan anti bakteri. Kondisi kulit liang telinga biasanya dalam kondisi kering sehingga menyebabkan risiko terjadinya serumen obsturan lebih cepat (Soepardi dkk, 2012).

Prevalensi World Health Organitation (WHO) pada tahun 2005 memperkirakan terdapat 278 juta orang di seluruh dunia mengalami gangguan pendengaran, 75-140 juta di antaranya terdapat di Asia Tenggara. Saat ini WHO memperkirakan ada 360 juta $(53 \%)$ orang di dunia mengalami gangguan pendengaran, 328 Juta (91\%) diantaranya adalah orang dewasa dan 32 juta (9\%) anak-anak. Karsmose dalam penelitian ACTA
Othorhinolaryngologica Italica tahun 2009 mengatakan dari 1.507 pasien yang mengalami gangguan pendengaran 2,1\% di antaranya ditemukan adanya serumen obsturan.

Data yang disajikan Riskesdas (2013) bahwa prevalensi kejadian serumen obsturan di Indonesia sebesar 18,8 \% dan prevalensi kejadian serumen obsturan di Kalimantan Selatan sebesar 25,5\%. insidensi serumen obsturan di Indonesia sebesar $18,7 \%$.

Prevalensi di RS Pertamina Bintang Amin Bandar Lampung mendapatkan pasien serumen obsturan sebanyak 17205 orang.

Di Indonesia, adanya sumbatan kotoran telinga atau serumen obsturan merupakan penyebab utama dari gangguan pendengaran pada sekitar 9,6 juta orang.

Berdasarkan survei cepat yang dilakukan Fakultas Kedokteran Indonesia (FK UI) di beberapa sekolah di enam kota di indonesia, prevalensi serumen obsturan pada anak sekolah cukup tinggi, yaitu antara 30-50\% (Kemenkes, 2013). 
Faktor resiko yang ditimbulkan oleh serumen obsturan yaitu pendengaran berkurang dan jika daun telinga ditarik maka suara yang kita dengarkan akan lebih jelas dan ada kalanya telinga berdengung, ini bisa menjadi tanda adanya serumen obsturan kemudian adanya rasa nyeri bila serumen obsturan menekan telinga begitu juga jika dilihat secara visual atau kasat mata terlihat adanya gundukan dalam liang telinga, namun harus dicek juga apakah keras atau lunak (Melinda, 2017)

Cotton bud adalah segumpal kecil kapas yang dibungkuskan pada satu atau kedua ujung tongkat pendek, biasanya terbuat dari kayu, kertas yang digulung, atau plastik (Mustofa, 2011).

Sebanyak 96\% alasan utama menggunakan cotton bud adalah untuk membersihkan telinga dari kotoran telinga (serumen), namun diketahui bahwa serumen diproduksi di bagian luar dari kanal dan bermigrasi dengan epitel menuju daun telinga dengan mekanisme alami (Nagala et al,2011)

Cotton bud biasa digunakan untuk membersihkan telinga dari Serumen dan kasus gatal pada telinga di kalangan masyarakat. Cotton bud tidak hanya digunakan oleh orang dewasa, tetapi juga digunakan oleh anak-anak. Mereka meyakini cotton bud merupakan sarana yang aman untuk membersikan telinga dan hidung (Kumar \& Ahmed, 2008)

Hasil penelitian yang dilakukan di India melaporkan bahwa terdapat asosiasi kuat secara statistik antara penggunaan cotton bud dengan serumen obsturan. Berbeda dari penelitian lainnya, penelitian oleh Brkic melaporkan frekuensi penggunaan cotton bud seminggu sekali tidak berhubungan dengan kejadian serumen obsturan pada anak-anak sekolah usia 7-10 tahun (Money dkk, 2018).
Adanya perbedaan dari hasil penelitian-penelitian sebelumnya mendorong peneliti ingin meneliti hubungan antara penggunaan cotton bud dengan serumen obsturan. Penelitian mengenai hubungan penggunaan cotton bud terhadap serumen obsturan pada populasi dewasa muda belum banyak dilaporkan (Money dkk, 2018).

Berdasarkan uraian di atas, maka peneliti tertarik untuk melakukan penelitian yang berjudul : "Hubungan antara penggunaan cotton bud dengan gangguan pendengaran terhadap pasien serumen obsturan di RS Pertamina Bintang Amin Bandar Lampung".

\section{METODE PENELITIAN}

Jenis penelitian yang digunakan dalam penelitian adalah analitik observasional. Rancangan penelitian ini menggunakan analitik observasional dengan pendekatan cross-sectional. Tempat penelitian dilakukan di RS Pertamina Bintang Amin Bandar Lampung. Penelitian dilaksanakan pada bulan juni-agustus 2020. Batasan atau kriteria yang menjadi populasi dalam penelitian ini adalah seluruh penderita serumen obsturan. Sampel yang digunakan pada penelitian ini 390 orang pasien serumen obsturan yang diambil dari kuisioner di RS Pertamina Bintang Amin Bandar Lampung. Adapun pengambilan sampel dilakukan dengan menggunakan teknik purposive sampling. Pada penelitian ini yang menjadi variabel dependennya adalah serumen obsturan dan variabel independennya adalah cotton bud. Dalam penelitian ini, pengambilan data primer dan sekunder dari wawancara dan rekam medik. Analisis data bivariat digunakan dalam penelitian ini adalah dengan uji Chi-square dengan bantuan program SPSS. 
HASIL DAN PEMBAHASAN

Penelitian dilakukan pada bulan Juni 2020 dengan mengambil data dari 390 orang pasien serumen obsturan yang diambil dari kuisioner di RS Pertamina Bintang Amin Bandar Lampung.

Analisis Univariat

Tabel 1.

Distribusi frekuensi Penggunaan Cotton Bud dan Serumen Obsturan di RS Pertamina Bintang Amin Bandar Lampung

\begin{tabular}{lcc}
\hline \multicolumn{1}{c}{ Penggunaan Cotton Bud } & Jumlah & Presentase \% \\
\hline Baik & 190 & 48.7 \\
Tidak Baik & 200 & 51.3 \\
\hline Serumen Obsturan & & \\
\hline Tidak Menutup Lubang (-) & 168 & 43,1 \\
Menutup Lubang (+) & 222 & 56,9 \\
& & \\
\hline Total & 390 & 100.0 \\
\hline
\end{tabular}

Berdasarkan tabel 1. di atas didapatkan dari 390 pasien serumen obsturan sebagian besar penggunaan cotton budnya tidak baik yaitu sebanyak 200 orang $(51,3 \%)$ dan sebagian besar penggunaan serumen obsturan menutup lubang yaitu sebanyak 222 orang $(56,9 \%)$.

\section{Analisis Bivariat}

Hubungan penggunaan cotton bud dengan serumen obsturan di RS Pertamina Bintang Amin Bandar Lampung

Tabel 2.

Hubungan Penggunaan Cotton Bud dengan Serumen Obsturan di RS Pertamina Bintang Amin Bandar Lampung

\begin{tabular}{|c|c|c|c|c|c|c|c|c|}
\hline \multirow{3}{*}{$\begin{array}{l}\text { Penggunaan } \\
\text { Cotton Bud }\end{array}$} & \multicolumn{6}{|c|}{ Serumen Obsturan } & \multirow{3}{*}{$\begin{array}{c}P \\
\text { value }\end{array}$} & \multirow{3}{*}{$\begin{array}{c}\text { OR } \\
95 \% \\
\mathrm{Cl}\end{array}$} \\
\hline & \multicolumn{2}{|c|}{$\begin{array}{l}\text { Tidak Menutup } \\
\text { Lubang }(-)\end{array}$} & \multicolumn{2}{|c|}{$\begin{array}{l}\text { Menutup } \\
\text { Lubang (+) }\end{array}$} & \multicolumn{2}{|c|}{ Total } & & \\
\hline & $\mathrm{n}$ & $\%$ & $\mathrm{n}$ & $\%$ & $\mathrm{n}$ & $\%$ & & \\
\hline - Baik & 103 & 54.2 & 87 & 45.8 & 190 & $\begin{array}{c}100 . \\
0\end{array}$ & 0,000 & $\begin{array}{l}2,45 \\
(1,6-\end{array}$ \\
\hline - Tidak Baik & 65 & 32.5 & 135 & 67.5 & 200 & $\begin{array}{c}100 . \\
0\end{array}$ & & $3,7)$ \\
\hline Total & 168 & 43.1 & 222 & 56.9 & 390 & $\begin{array}{c}100 . \\
0\end{array}$ & & \\
\hline
\end{tabular}

Berdasarkan hasil analisa, diketahui bahwa dari 190 responden yang menggunakan cotton bud baik, didapatkan 103 responden (54,2\%) serumen obsturan tidak menutup lubang (-). Sedangkan dari 200 responden yang menggunakan cotton bud baik, didapatkan 135 responden
$(67,5 \%)$ serumen obsturan menutup lubang (+). Hasil uji statistik diperoleh nilai $p$ value 0,000 maka dapat disimpulkan bahwa ada hubungan penggunaan cotton bud dengan serumen obsturan di RS Pertamina Bintang Amin Bandar Lampung. Hasil analisis diperoleh pula nilai OR 2,45 
$(95 \% \mathrm{Cl} 1,63-3,7)$ yang berarti bahwa responden yang menggunakan cotton bud tidak baik 2,45 kali lebih besar serumen obsturan menutup lubang $(+)$. dibandingkan dengan yang yang menggunakan cotton bud baik.

\section{PEMBAHASAN}

Hasil penelitian menunjukkan ada hubungan penggunaan cotton bud dengan serumen obsturan di RS Pertamina Bintang Amin Bandar Lampung. Hasil analisis diperoleh pula nilai OR 2,45 (95\% Cl 1,63-3,7) yang berarti bahwa responden yang menggunakan cotton bud tidak baik 2,45 kali lebih besar serumen obsturan menutup lubang (+). dibandingkan dengan yang yang menggunakan cotton bud baik.

Kulit pada meatus austikus eksternus secara histologi hampir sama dengan kulit tubuh lainnya, bagian yang membedakan adalah tebal tipisnya lapisan epidermis pars ossea. Hal tersbeut merupakan faktor terjadinya kerusakan kulit pada meatus austikus eksternus meskipun oleh trauma yang kecil. Kebiasaan mengorek-orek telingan dengan lidi kapas/cotton buds dapat menyebabkan terjadinya laserasi pada epidermis sehingga memudahkan terjadinya invasi kuman pada kulit meatus austikus eksternus. Selain itu mengorek telinga dapat menyebabkan hilangnya protctive Lipis Leyer And Acid Mantle. Hal teresebut menyebabkan kelembaban dan suhu meatus austikus eksternus meningkat. Bentuk meatus austikus eksternus yang lembab, hangat dan kotor merupakan media pertumbuhan kuman yang baik (Rukmini, 2005).

Serumen (earwax), dengan kandungan lisosom, glikoprotein, imunoglobulin, lipid, elemen, serta $\mathrm{pH}$ 4-5, berfungsi untuk membersihkan, melumasi, dan melindungi saluran pendengaran eksternal. Zat ini terbentuk ketika terjadi campuran antara sekresi kelenjar dari saluran telinga luar dengan epitel skuamosa yang terkelupas. Pergerakan rahang selama mengunyah dan berbicara mendorong migrasi ini. Bahan-bahan asing melekat pada serumen, mencegahnya dari memasukkan ke dalam telinga atau mencapai membran timpani. Proses ini merupakan mekanisme pembersihan diri kanalis auditorius eksternal. Self-ear cleaningadalah tindakan memasukkan benda ke telinga dengan tujuan membersihkannya. Pembersihan telinga yang berlebihanmeningkatkan kelembapan dan melicinkan liang telinga, serta menyebabkan infeksi dan iritasi pada telinga yang menyebabkan perubahan pada lapisan kulit dan dengan demikian merusak fungsi pembersihan alami. Upaya membersihkan saluran telinga atau menghilangkan kotoran dengan menggunakan alat seperti cotton bud dan loose cotton swab tip, bulu, tongkat dan berbagai objek lainnya menimbulkan risiko trauma dan cedera pada telinga, termasuk nyeri, sakit telinga, perdarahan, perforasi membran timpani dan melemahnya pertahanan lokal saluran pendengaran eksternal terhadap infeksi bakteri dan jamur.

Rata-rata orang menggunakan cotton bud untuk membersihkan telinganya sendiri. Tetapi, penggunaan cotton bud tidak dapat membersihkan serumen secara sempurna, sebagian akan tertinggal dan akan menyebabkan terjadinya penumpukan serumen jika tidak dikeluarkan semua. Faktor predisposisi terjadinya serumen obsturan adalah persepsi dan cara yang salah dalam membersihkan telinga dengan menggunakan cotton bud. Serumen dapat keluar sendiri dari kanalis akustikus eksterna akibat migrasi epitel kulit yang bergerak dari arah membran menuju ke luar serta dibantu gerakan rahang sewaktu 
mengunyah. Jika proses ini terganggu akibat adanya faktor dari luar seperti kebiasaan membersihkan telinga menggunakan cotton bud ataupun benda tajam yang dapat merusak lapisan epidermis sehingga proses migrasi terganggu ditambah produksi serumen yang terus terjadi maka akan menyebabkan penumpukan dan sumbatan serumen pada kanalis akustikus eksterna.

Hasil penelitian ini sejalan dengan penelitian Money (2018) tentang Hubungan Antara Penggunaan Cotton Bud Dengan Serumen Obsturan, dimana analisis data menunjukan $14.5 \%$ sampel menderita serumen obsturan pada telinga kanan dan $8.7 \%$ sampel menderita serumen obsturan pada telinga kiri. Berdasarkan uji statistik didapatkan hubungan bermakna kedalaman penggunaan cotton bud dengan serumen obsturan pada telinga kanan $(p=0,012)$ dan telinga kiri $(p=0,037)$. Terdapat hubungan bermakna frekuensi penggunaan cotton bud dengan serumen obsturan pada telinga kanan $(p=0,001)$, namun tidak pada telinga kiri. Tidak terdapat hubungan bermakna durasi penggunaan cotton bud dengan serumen obsturan pada telinga kanan dan telinga kiri. Kesimpulan: terdapat hubungan bermakna kedalaman dan frekuensi penggunaan cotton bud dengan serumen obsturan pada telinga kanan. Pada telinga kiri hanya variabel kedalaman yang memiliki hubungan bermakna dengan serumen obsturan.

Serumen di produksi oleh glandula seruminosa dan glandula sebasea yang terletak pada sepertiga lateral kanalis auditori eksternus. Penggunaan cotton bud yang dalam pada kanalis auditori eksternus akan melawan proses pembersihan alami kanalis auditori eksternus dan mendorong serumen semakin ke medial sehingga menyebabkan terbentuknya serumen obsturan.
Hasil penelitian ini didukung penelitian di Iran yang menyatakan bahwa penggunaan benda asing seperti cotton bud untuk membersihkan telinga secara frequent setelah mandi berhubungan dengan inflamasi pada kanalis auditori eksternus. Penelitian sebelumnya melaporkan bahwa membersihkan telinga yang terlalu sering dapat mengganggu barrier protektif pada kanalis auditori eksternus dan meningkatkan kelembaban pada kanalis auditori eksternus. Inflamasi dan kelembaban pada kanalis auditori eksternus akan merangsang peningkatan produksi serumen dan menyebabkan terbentuknya serumen obsturan.

Pada penelitian ACTA tahun 2009 mengatakan bahwa pasien yang sering menggunakan cotton buds untuk membersihkan telinganya akan menekan serumen kearah membran timpani, Hingga membuat pengeluarannya semakin sulit akibatnya serumen akan terjebak dan terakumulasi sehingga akhirnya menyebabkan sumbatan telinga. Kasus tuli konduktif akan timbul jika serumen yang ada di liang telinga adalah serumen obturans seperti hasil penelitian J.A.E Eziyi et al tahun 2011 Yang didapatkan hasil pada serumen Obturans jumlah penderita yang mengalami tuli konduktif kiri sebanyak 50,5\%, kanan 45\% dan keduanya sebanyak 4,1\%. Pada kebiasaan membersihkan telinga dengan cotton buds dengan serumen prop (serumen kental dan kuning) belum berdampak pada tuli koduktif hal itu disebabkan karena pada mekanisme mendengar belum terhambat. 


\section{KESIMPULAN DAN SARAN}

\section{Kesimpulan}

1. Berdasarkan tabel 4.1 di atas didapatkan dari 390 pasien serumen obsturan sebagian besar penggunaan cotton budnya tidak baik yaitu sebanyak 200 orang (51,3\%).

2. Berdasarkan tabel 4.2 di atas didapatkan dari 390 pasien serumen obsturan sebagian besar penggunaan serumen obsturan menutup lubang yaitu sebanyak 222 orang $(56,9 \%)$

3. Ada hubungan penggunaan cotton bud dengan serumen obsturan di RS Pertamina Bintang Amin Bandar Lampung. Hasil analisis diperoleh pula nilai OR 2,45 $(95 \% \mathrm{Cl} 1,63-$ 3,7 ) yang berarti bahwa responden yang menggunakan cotton bud tidak baik 2,45 kali lebih besar serumen obsturan menutup lubang (+). dibandingkan dengan yang yang menggunakan cotton bud baik.

\section{Saran}

1. Diharapkan bagi peneliti selanjutnya dapat menggunakan metode penelitian yang menghubungkan sebab akibat secara lebih kuat, seperti metode cohort.

2. Untuk mengurangi bias pada penelitian selanjutnya, penegakan diagnosis serumen obsturan dilakukan oleh dua pemeriksa.

3. Pada penelitian selanjutnya perlu dilakukan eksklusi untuk sampel dengan eksema.

\section{DAFTAR PUSTAKA}

Agustina, Rismia, and Hasby Pri Choiruna. (2019) "Faktor-Faktor Yang Berhubungan Dengan Terbentuknya Serumen Obsturan Di Rsud Brigjend $\mathrm{H}$.
Hasan Basry Kandangan." Nerspedia Journal 2.1 : 69-76.

Alriyanto, C. Yuniardi. (2010) Pengaruh Serumen Obsturan Terhadap Gangguan Pendengaran (Studi Kasus Pada Siswa Kelas V SD di Kota Semarang). Diss. Faculty of Medicine.

Asri, Pivi Money, Zulfikar Naftali, and Dwi Marliyawati. (2018) "hubungan antara penggunaan cotton bud dengan serumen obsturan." jurnal kedokteran diponegoro 7.2: 892-905.

Ballenger JJ. (1994) Penyakit Telinga Hidung Tenggorok Kepala Dan Leher.Edisi13. Jakarta: Binarupa Aksara;.

Charisma, Puteri Moetia. (2016). "hubungan serumen obsturan dengan gangguan pendengaran di madrasah ibtidaiyah negeri ulee kareng." etd Unsyiah.

Departemen Kesehatan RI. (2010) Telinga Sehat Pendengaran Baik. Depkes RI. Jakarta.

Guest J.F, Greener MJ, Robinson AC \& Smith AF. (2004). Impacted Cerumen: Composition, Production, Epidemiology, and Management. Q.J. Med: 97(8): 477-88.

Hafil; A; F. Sosialisman; Helmi (2012). Buku ajar ilmu kesehatan: telinga hidung tenggorokan kepala dan leher. Edisi 7. Jakarta: FK UI. P 50-56

Kemenkes, RI. (2013). Gangguan Telinga bikin Anak Sulit Menangkap Pelajaran di Sekolah. Pusat Komunikasi Publik Setjen Kemenkes RI.

Kumar, G., Majumdar, A., \& Pavithra, G. (2008). Quality of life (QOL) and its associated factors using WHOQOL-BREF among elderly in Urban Puducherry, India. Original Articel, 8(1), 54-5

Maharddhika, Manggala. (2010) Faktor-faktor yang Mempengaruhi Pembentukan 
Serumen Obsturan (Studi Kasus pada Siswa SD Kelas $V$ di Kota Semarang). Diss. Faculty of Medicine.

McCarter, D. \& Susan, M., (2007). Cerumen Impaction. American Family Physician, 75(10).

Mescher AL. (2013) Janquiera's Basic Histology Text and Atlas. 13th ed. Newyork : Mc.Graw Hill,. 497499p.

Miura T, Ichiki $\mathrm{H}$, Hashimoto I, et al. (2007) Antidiabetic activity of a xanthone compound, mangiferin. Phytomedicine; 8 (2) : 85-87. Morsi, R.M.Y., ElTahan, N.R., dan El-Hadad, A.M.A. 2010. Effec

Money P, Naftali Z, Marliyawati D. (2018). Hubungan antara Penggunaan Cotton Bud dengan Serumen Obsturan.

Notoatmodjo, P.D., (2017). Metodologi Penelitian Kesehatan. Jakarta: PT Rineka Cipta.

Paulsen; F. Waschke; J (2015). Sobotta atlas anatomi manusia kepala leher dan neuroanatomi. Jilid 3. Jakarta EGC. P 136-157

Persaud, R. A. P., et al. (2004). "Keratosis obturans and external ear canal cholesteatoma: how and why we should distinguish between these conditions." Clinical Otolaryngology \& Allied Sciences 29.6: 577-581.

Rahmi, Trisna Yussy. (2016) Gambaran Perilaku Siswa SMA di Kota Padang Terhadap Penggunaan Cotton Bud. Diss. Universitas Andalas,.

Saloranta, K., and T. Westermarck. (2005) "Prevention of cerumen impaction by treatment of ear canal skin. A pilot randomized controlled study." Clinical Otolaryngology 30.2: 112-114.

Schumacher, Anamur Lan, Georg Ledderose, and Karl-Joseph Paquet. (2010) Hals-Nasen-
Ohren-Heilkunde. KVM, der Medizinverl.

Sharma, Rajnish Chander. (2014) "Is Keratosis obturans a predisposing factor for external auditory canal cholesteatoma: Some interesting cases." Indian Journal of Otology 20.3: 99.

Soepardi EA, Iskandar N, Bashiruddin J, Restuti RD. (2012). Buku Ajar Ilmu Kesehatan THT-KL FK UI. Dalam: Gangguan Pendengaran dan Kelainan Telinga. Edisi ketujuh. Jakarta: Badan Penerbit FKUI;. h. 10-38

Soetirto I, Hendarmin H, Bashiruddin J. Gangguan Pendengaran (Tuli). In: Soepardi EA, Iskandar $\mathrm{N}$, Bashiruddin J, Restuti RD. (2007). Buku Ajar Ilmu Kesehatan Telinga Hidung Tenggorok Kepala dan Leher. Jakarta: Badan Penerbit FK UI. p.13-16.

Sugiyono. (2010). Metode Penelitian Pendidikan Pendekatan Kuantitatif, kualitatif, dan R\&D. Bandung: Alfabeta

Syahrijuita, Syahrijuita, et al. (2011) "Perbandingan Efektivitas

Beberapa Pelarut Terhadap Kelarutan Cerumen Obturans Secara In Vitro." Majalah Kesehatan Pharmamedika 3.1: 217-221.

Tortora, G. J., \& Derrickson, B (2009). Principles of Anatomy \& Physiology. USA: John Wiley \& Sons. Inc.

Vivien R,Ismelia F. (2013) Gejala Serumen Obsturan Dan Perilaku Terhadap Membersihkan Telinga Di Poliklinik THT RSUD Raden Mattaher Jambi. Jambi:Fakultas Kedokteran Dan Ilmu Kesehatan Universitas Jambi.

WHO. (2015). Hearing Loss Due to Recreational Exprosure to Loud Sounds. 